\title{
Erratum
}

\section{Health in all policies? The case of policies to promote bicycle use in the Netherlands}

Lea den Broeder, Eline Scheepers, Wanda Wendel-Vos and Jantine Schuit

Journal of Public Health Policy (2015) 36, 375-379. doi:IO.I057/jphp.20I 5.20; published online 2 July 2015

Correction to: Journal of Public Health Policy 36(2): I94-2I I; advance online publication, 5 February 20I 5; doi: I0.1057/jphp.20I4.55

We regret that we, the Editors and Publisher, failed to see and correct a typesetting error where some shading from the original submission was omitted. This is now corrected herein, with our apologies to the authors and readers for any confusion caused.

No other changes to the article have been made. 
Table I: Policies relevant to active transport

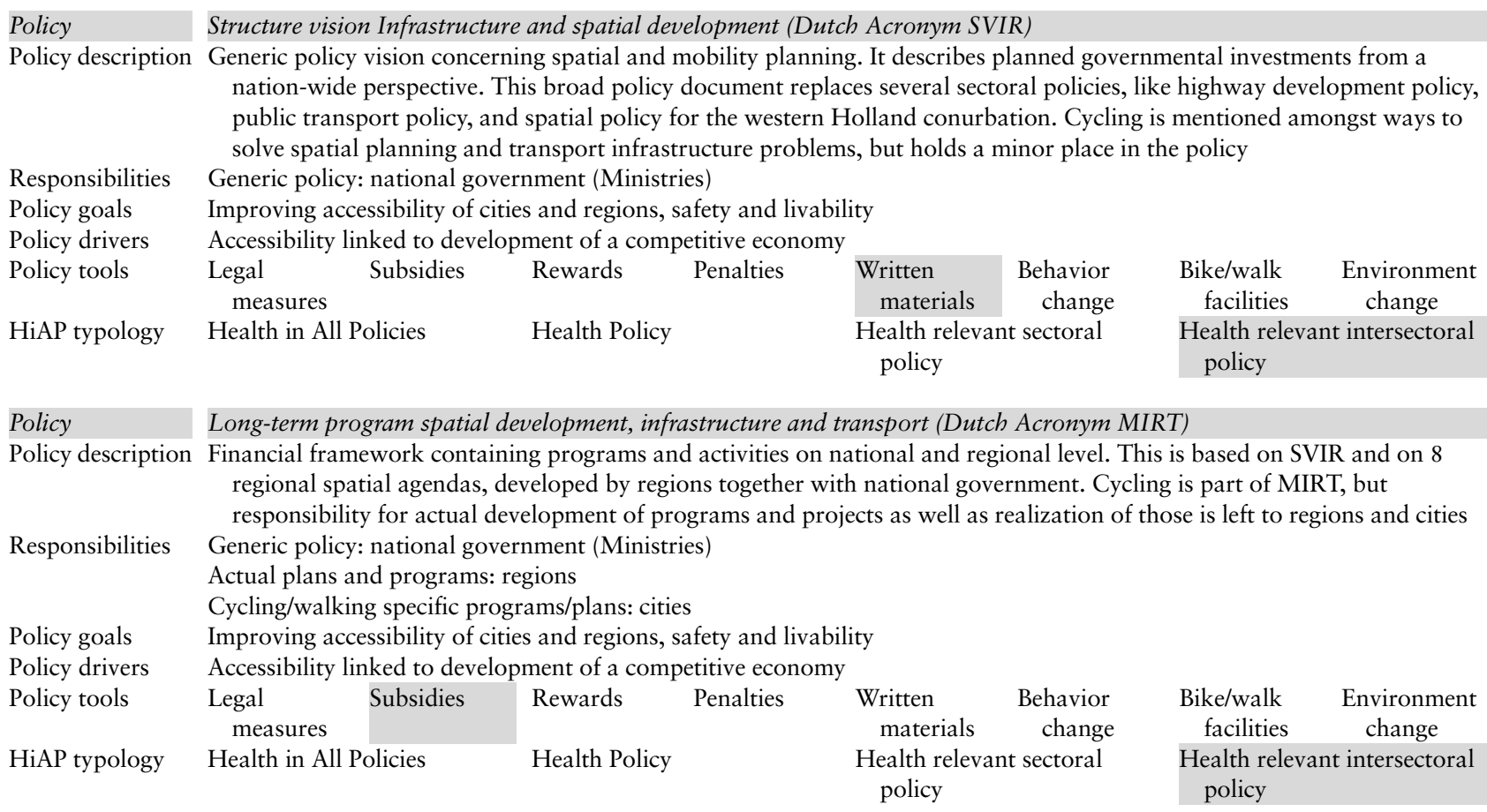




\section{Policy Regional spatial agendas}

Policy description Eight regions develop a vision for future development and implement this in local projects, linked to their specific context and problems. These agendas have no legal basis, but serve as agenda setting for negotiations with the Ministry in the MIRT framework. They do not contain new policy developments

Responsibilities Eight regions are each responsible for their own spatial agenda. They work with municipalities to develop these

Policy goals Different policy goals for each region. Examples: protection against flooding, livability of the region, sustainability

Policy drivers Accessibility linked to development of a competitive economy, livability for citizens

Policy tools

Legal

Subsidies

Rewards

Penalties

$\begin{gathered}\text { Written } \\ \text { materials }\end{gathered} \begin{array}{r}\text { Behavior } \\ \text { change }\end{array}$
Health relevant sectoral

Bike/walk

Environment

measures

HiAP typology Health in All Policies Health Policy policy

change

Health relevant intersectoral policy

Policy

\section{Better use (of transport infrastructure)}

Policy description Generic policy vision linked to concrete measures in transport infrastructure: road, rail, air, and water. It contains budgets spent on projects and activities fitting this policy vision

Responsibilities Generic policy and large infrastructural projects: national government

Infrastructural projects on regional scale: provinces

Municipalities and provinces cooperate where local issues are linked to this vision

Policy goals Reduce traffic jams by 20 per cent, efficient use of infrastructure, improvement of accessibility

Policy drivers Accessibility linked to development of a competitive economy (brainports and mainports)

Policy tools

Legal

Subsidies

Rewards

Penalties

Written

Behavior

Bike/walk

Environment

HiAP typology

Health in All Policies Health Policy

Health relevant sectoral

policy facilities change

Health relevant intersectoral policy 
Table I: Continued

\section{Policy Space for bikes}

Policy description Program to improve bicycle facilities at railway stations, in particular bike parks.

Responsibilities National Government in cooperation with Prorail (rail infrastructure company) and Dutch Railways Company. Coordination with municipalities

Policy goals Increase number of train passengers

Policy drivers Reduce pressure on motorways: accessibility. Financial: rail efficiency, economic development.

Policy tools Legal Subsidies Rewards Penalties Written Behavior Bike/walk Environment measures materials change facilities change

HiAP typology Health in All Policies Health Policy Health relevant sectoral Health relevant intersectoral policy policy

Policy Safe traffic action program

Policy description Long term program to reduce accidents. Contains budgets for risk reducing measures in traffic. Accidents are monitored. The program contains accident reduction ambitions

Responsibilities National government (program coordination and measures on large infrastructural facilities)

Provinces: coordination and implementation on provincial level

Municipalities: coordination and implementation of local level measures

Policy goals Reduce number of traffic accidents

Policy drivers Reduce number of people injured or killed in traffic accidents

Policy tools

Legal Subsidies $\quad$ Rewards Penalties

$\begin{array}{lll} & \text { measures } & \\ \text { HiAP typology } & \text { Health in All Policies Policy }\end{array}$

$\begin{array}{cc}\text { Written } & \text { Behavior } \\ \text { materials } & \text { change }\end{array}$

Health relevant sectoral

policy
Bike/walk

Environment

facilities change

Health relevant intersectoral policy 


\section{Policy Climate agenda}

Policy description Broad policy focusing transport, housing, industry and energy, agriculture, linked up to European climate targets

Responsibilities National government: rules and regulations and financial measures contributing to $\mathrm{CO}_{2}$ reduction

Provinces and cities are stimulated to develop their own climate agendas.

Private sector is explicitly seen as a partner.

Policy goals

Reduce $\mathrm{CO}_{2}$ emission

Policy drivers Adhere to EU targets, sustainability

Policy tools$$
\text { Legal Subsidies Reward }
$$

measures

HiAP typology

Health in All Policies

Health Policy

Penalties

$\begin{gathered}\text { Written } \\ \text { materials }\end{gathered}$
$\begin{gathered}\text { Behavior } \\ \text { change }\end{gathered}$
Health relevant sectoral

Bike/walk

facilities

Environment

Health relevant sectoral

policy

Policy

Action agenda architecture and spatial design

Policy description Policy vision on future development of local (urban) environments. It includes views on development of multi transport networks that provide opportunities to further develop urban conglomerates, as well as creation of multimodal focal points where intensive transport is needed.

Responsibilities National government together with municipalities, some connection to provincial policies.

Policy goals

Policy drivers

Adapt to cultural, technological, demographic developments

Policy tools

and economic progress

Legal

Subsidies

Rewards Penalties

measures

HiAP typology

Health in All Policies

Health policy

Bike/walk

facilities

Environment

Health relevant sectoral

policy
Health relevant intersectora policy 